http://dx.doi.org/10.32929/2446-8355.2020v29n3p300-312

\title{
CARACTERÍSTICAS MORFOFISIOLÓGICAS DA SOJA EM LATOSSOLO AMARELO SUBMETIDA A DIFERENTES FONTES DE FERTILIZANTES FOSFATADOS NO CERRADO PIAUIENSE
}

Adaniel Sousa dos Santos ${ }^{1}$, Leandro Pereira Pacheco ${ }^{2}$, Wéverson Lima Fonseca ${ }^{3}$, Alan Mario Zuffo $^{4^{*}}$, João Batista da Silva Oliveira ${ }^{5}$, Júlio César Azevedo Nóbrega ${ }^{6}$, Francisco de Alcântara Neto ${ }^{7}$, Rafael Felippe Ratke ${ }^{8}$, Tiago de Oliveira Sousa ${ }^{9}$, Aline Sousa dos Santos ${ }^{10}$

${ }^{1}$ Doutorando, Agronomia, Universidade Federal do Piauí (UFPI), Bom Jesus, PI.

2 Docente, Fitotecnia, Universidade Federal de Rondonópolis (UFR), Rondonópolis, MT.

${ }^{3}$ Docente, Fitotecnia, Universidade Federal do Piauí (UFPI), Colégio Técnico de Bom Jesus (CTBJ), Bom Jesus, PI.

${ }^{4}$ Docente, Fitotecnia, Universidade Federal de Mato Grosso do Sul (UFMS), Chapadão do Sul, MS. *E-mail do autor correspondente: alan_zuffo@hotmail.com

${ }^{5}$ Mestre, Fitotecnia, Universidade Federal do Piauí (UFPI), Bom Jesus, PI.

${ }^{6}$ Docente, Fertilidade do solo, Universidade Federal do Recôncavo da Bahia, Cruz das Almas, BA.

${ }^{7}$ Docente, Fitotecnia, Universidade Federal do Piauí (UFPI), Teresina, PI.

${ }^{8}$ Docente, Fertilidade do solo, Universidade Federal de Mato Grosso do Sul (UFMS), Chapadão do Sul, MS.

${ }^{9}$ Doutorado, Produção Vegetal, Universidade Federal dos Vales do Jequitinhonha e Mucuri (UFVJM), Diamantina, MG.

${ }^{10}$ Graduada, Ciências Biológicas, Universidade Federal do Piauí (UFPI), Bom Jesus, PI.

Recebido: 07/12/2018; Aceito: 09/07/2020

RESUMO: As fontes de fertilizantes fosfatados apresentam diferenças no produto das reações químicas entre o fertilizante e o solo, sendo influenciadas pelas características químicas e texturais do solo. Nesse sentido, objetivou-se com este estudo avaliar características morfofisiológicas da cultura da soja sob diferentes fontes de fósforo no sudoeste piauiense. O delineamento experimental foi em blocos casualizados, sendo que os tratamentos constaram de quatro fontes de fósforo (o superfosfato simples (SSP), o superfosfato triplo (SPT), fosfato natural reativo (FNR) e o fosfato natural reativo + enxofre $(\mathrm{FNR}+\mathrm{S})$ ), mais uma testemunha com calcário Cincal, com quatro repetições. $\mathrm{O}$ experimento foi implantado no ano agrícola 2012/13 e as avaliações foram realizadas durante as safras 2013/14 e 2014/15. Foram avaliadas variáveis do estádio fenológico de florescimento pleno e de produção da soja. As características morfofisiológicas da cultura da soja foram influenciadas pelas fontes de fósforo, conforme constatado no estande de plantas, índice de área foliar, radiação fotossintética ativa e eficiência da radiação fotossintética ativa, fitomassa seca, produtividade e no peso de mil grãos.

Palavras-chave: Glycine max. Nutrientes. Fósforo. Produtividade.

\section{MORPHOPHYSIOLOGICAL CHARACTERISTICS OF SOYBEAN IN YELLOW LATOSOL SUBMITTED TO DIFFERENT SOURCES OF PHOSPHATE FERTILIZERS IN THE PIAUÍ CERRADO}




\begin{abstract}
The sources of phosphate fertilizers present differences in the product of the chemical reactions between the fertilizer and the soil, being influenced by the chemical and textural characteristics of the soil. In this sense, this study's objective was to evaluate the morphophysiological characteristics of the soybean crop under different phosphorus sources in southwest Piauí. The experimental design was a randomized complete block design. The treatments consisted of four phosphorus sources (single superphosphate (SSP), triple superphosphate (SPT), natural reactive phosphate (FNR), and natural reactive phosphate + sulfur $(\mathrm{FNR}+\mathrm{S}))$, plus one control with limestone Cincal, with four replicates. The experiment was implemented in the agricultural year 2012/13, and the evaluations were carried out during the 2013/14 and 2014/15 seasons. Variables of the phenological stage of full flowering and soybean production were evaluated. The morphophysiological characteristics of the soybean crop were influenced by the sources of phosphorus, as verified in the plant stand, leaf area index, active photosynthetic radiation, and the efficiency of active photosynthetic radiation, dry phytomass, productivity and the weight of a thousand grains.
\end{abstract}

Key words: Glycine max. Nutrients. Phosphorus. Productivity.

\title{
INTRODUÇÃO
}

A cultura da soja (Glycine max L.) ocupa lugar de destaque na agricultura brasileira, sendo o mais importante produto de exportação do Brasil. Em seu último relatório, o Departamento de Agricultura dos Estados Unido (UNITED STATES DEPARTMENT OF AGRICULTURE - USDA, 2018) projetou que o Brasil passará a ser o maior produtor mundial, com produção de 117 milhões de toneladas na safra 2018/2019.

O crescimento da cultura no país se deve aos avanços científicos e a disponibilização de tecnologias ao setor produtivo. Entre os fatores, está associado a mecanização e a criação de cultivares mais produtivos adaptados às diversas regiões, o desenvolvimento de pacotes tecnológicos relacionados ao manejo de solos e ao manejo de adubação e calagem (FREITAS et al., 2011).

A expansão da soja no Brasil ocorre no cerrado onde predominam solos altamente intemperizados, como os Latossolos. Estes solos apresentam como características químicas de uma forma geral a acidez, de serem lixiviados, pobres em nutrientes, especialmente em fósforo (P) disponível para as plantas. Com isso, torna-se necessário, elevados investimentos iniciais em corretivos e fertilizantes, bem como adubações anuais para corrigir deficiências e desequilíbrios nutricionais que possam afetar o desenvolvimento e consequentemente a produção da cultura.

Dentre os investimentos iniciais na produção, o fornecimento de fósforo representa parte expressiva do custo de produção das culturas, especialmente nas regiões tropicais e na quase totalidade nos solos da região do cerrado brasileiro, pois além de apresentarem baixa disponibilidade de fósforo (P), são intemperizados, ácidos, argilosos e oxídicos, características que favorecem a fixação do fósforo pelo solo (SILVA et al., 2011). A implicação prática disso é que, embora a exigência de fósforo pelas plantas não seja elevada, 
grandes quantidades do nutriente devem ser fornecidas nas adubações para promover alguma saturação do solo e originar um excedente que atenda aos requerimentos nutricionais das culturas (NOVAIS et al., 2007).

Os fertilizantes fosfatados podem ser diferenciados pelo potencial de solubilidade, podendo seu comportamento variar em cada tipo de solo. As fontes superfosfato simples (SSP), superfosfato triplo (SST), fosfato natural reativo (FNR) e o fosfato natural reativo + enxofre (FNR+S), são bastante acessíveis na região do Cerrado sudoeste do Piauí. Entretanto, com base nos problemas observados em campo sobre a dificuldade e a resposta diferencial do conhecimento da melhor fonte para se produzir de maneira rentável, objetivou-se com este estudo avaliar características morfofisiológicas da cultura da soja sob diferentes fontes de fósforo no Cerrado sudoeste do Piauí.

\section{MATERIAL E MÉTODOS}

\section{Localização do experimento}

O experimento foi realizado nos anos agrícolas 2013/14 e 2014/15, na Fazenda Marafon (Serra do Quilombo), localizado no município de Bom Jesus, Estado do Piauí, Brasil, e as

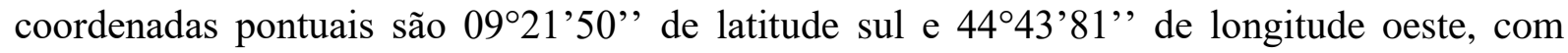
altitude média de $550 \mathrm{~m}$. O solo foi classificado como Latossolo Amarelo distrófico - LAd, textura franco arenosa (argila: 90, silte: 30 e areia: $880 \mathrm{~g} \mathrm{~kg}^{-1}$ ). Antes da calagem, e após a limpeza da vegetação nativa, realizou-se uma análise química, cuja composição apresentou: pH $\left(\mathrm{CaCl}_{2}\right): 4,35 ; \mathrm{P}$ (Mehlich): 0,66 mg dm${ }^{-3} ; \mathrm{K}^{+}: 10,77 \mathrm{mg} \mathrm{dm}^{-3} ; \mathrm{Ca}^{2+}: 0,4 \mathrm{cmolc} \mathrm{dm}^{-3}$; $\mathrm{Mg}^{2+}: 0,1 \mathrm{cmolc} \mathrm{dm}^{-3}$; Al: 0,65 cmolc dm${ }^{-3}$; (H+Al): 4,9 $\mathrm{cmolc} \mathrm{dm}^{-3}$; SB: 0,5 cmolc dm ${ }^{-3}$; t:1,15 cmolc dm $\mathrm{dm}^{-3} \mathrm{~T}: 5,41 \mathrm{cmolc} \mathrm{dm}^{-3}$; V: 9,33\% e m: 56,31\%. O clima da região é do tipo Aw, segundo a classificação climática global de Köppen, com duas estações bem definidas, sendo uma seca, que vai de maio a setembro, e outra chuvosa, que vai de outubro a abril. Os dados de precipitação acumulada durante a realização do experimento encontram-se na Figura 1 .

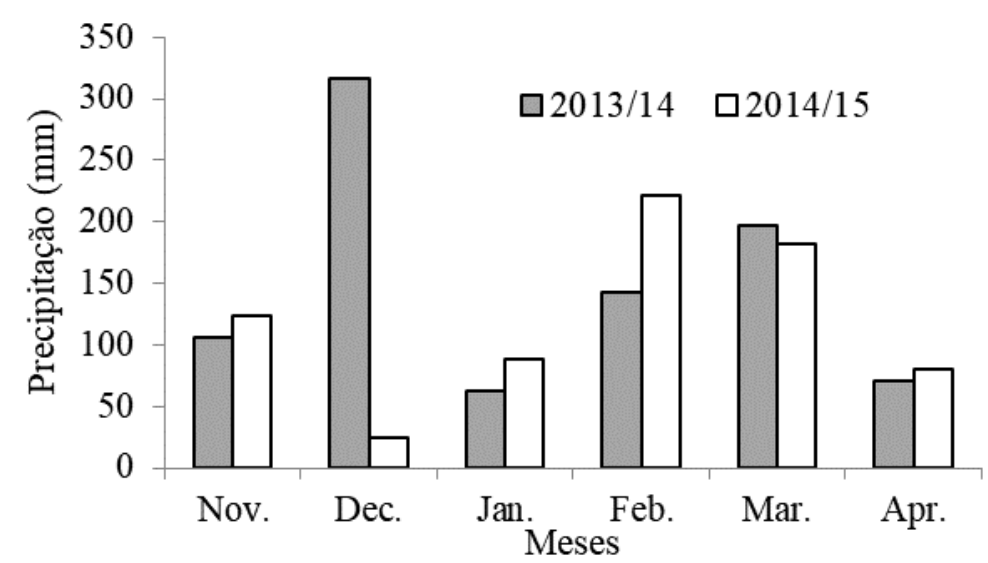

Figura 1. Médias mensais de precipitação pluvial, ocorridas na Fazenda Marafon nos anos agrícolas 2013/14 e 2014/15, durante a realização dos experimentos. Monthly averages of rainfall, occurring in Marafon Farm, 2012/13 cropping season, during experiment conduction.

Fonte: Autoria própria. Own authorship. 


\section{Condução do experimento}

A implantação do experimento teve início no ano agrícola (2012/13) realizando a calagem, utilizando o calcário Cincal em toda a área experimental. Em seguida, foi feito o preparo do solo, realizado com aração mecanizada na profundidade de 0-20 cm.

O delineamento experimental foi em blocos casualizados, sendo que os tratamentos constaram de quatro fontes de fósforo, mais uma testemunha com calcário Cincal, com quatro repetições, perfazendo-se 20 parcelas $(25 \mathrm{~m} \times 12 \mathrm{~m})$. As fontes de fósforo testadas foram o superfosfato simples (SSP), o superfosfato triplo (SPT), fosfato natural reativo (FNR) e o fosfato natural reativo + enxofre $(\mathrm{FNR}+\mathrm{S})$, com as seguintes formulações e dosagens: 00:18:00/550kg; 00:43:00/230kg; 00:29:00/710kg; e 00:26:00/710kg, respectivamente.

Após a aplicação dos tratamentos, realizada no dia 26 de novembro de 2012, foi cultivado a cultura do arroz. No ano seguinte, iniciou-se os tratamentos com o cultivo da soja durante duas safras (2013/14 e 2014/15), avaliando o efeito das fontes de fósforo.

A semeadura da soja foi realizada nos dias 02 e 06 de dezembro, respectivamente em cada ano agrícola. A adubação foi constituída de $350 \mathrm{~kg} \mathrm{ha}^{-1}$ do formulado de $\mathrm{N}-\mathrm{P}_{2} \mathrm{O}_{5}-\mathrm{K}_{2} \mathrm{O}$ (02-30-20), aplicado via sulco. As sementes foram inoculadas com bactérias Bradyrhizobium japonicum, na dose de $3 \mathrm{~mL}$ p. c. $\mathrm{kg}^{-1}$ de semente - estirpes SEMIA 5079 e 5080, do inoculante Nitragin Cell Tech $\mathrm{HC}^{\circledR}\left(3 \times 10^{9} \mathrm{UFC} / \mathrm{mL}\right)$. A semeadura foi realizada com uso de semeador-adubadora, utilizando-se a cultivar MONSOY 9350. Cada parcela foi constituída de 24 linhas de semeadura de $25 \mathrm{~m}$ de comprimento, espaçadas de $0,50 \mathrm{~m}$, tendo a área de cada parcela $300 \mathrm{~m}^{2}(25 \mathrm{~m} \mathrm{x} 12 \mathrm{~m})$. Como área útil foi considerada as duas fileiras centrais. Manteve-se estande de 12 plantas $\mathrm{m}^{-1}$, densidade populacional de 240.000 plantas ha $^{-1}$.

Os tratos culturais (controle de plantas daninhas, pragas e doenças) anteriores e posteriores a semeadura foram os recomendados para a região e, conforme as necessidades da cultura.

\section{Variáveis analisadas}

No início da floração $\left(\mathrm{R}_{1}\right)$ foi determinado: estande de plantas - foi avaliado 4 pontos aleatórios em cada unidade experimental. Em cada ponto foi realizada a contagem das plantas utilizando uma linha métrica de $2 \mathrm{~m}^{-1}$; fitomassa seca de parte aérea - realizou-se a coletada de 5 plantas por unidade experimental. Logo após, foram colocadas em um saco de papel modelo 'Kraft' e, levadas a estufa de circulação de ar forçado $60^{\circ} \mathrm{C}$, durante 72 horas até obtenção de massa constante, com posterior pesagem dos resíduos vegetais; índice de área foliar - determinada com medidor de área foliar eletrônico modelo Li-Cor, L1-3100 ${ }^{\circledR}$. Em seguida, foi determinada a massa seca em estufa de circulação forçada de ar a $65{ }^{\circ} \mathrm{C}$ até obtenção do peso constante. Por meio da área das folhas, calculou-se a área total de folhas da amostra e, com posterior leitura e ajuste na equação (IAF igual soma de toda superfície foliar * Área do Solo ${ }^{-1}$ ). IAF correspondente $\left(\mathrm{m}^{2}\right.$ de folhas $\mathrm{m}^{-2}$ de solo).

Teor de clorofila - foram determinadas indiretamente, por meio de um medidor portátil de clorofila (ClorofilLOG CSL1030). As avaliações foram realizadas em quatro pontos 
aleatórios por parcela, medindo-se 3 pontos em diferentes partes na mesma folha e sempre no limbo foliar entre as nervuras no terceiro trifólio de cima para baixo.

Radiação fotossintética ativa - foi determinada com o uso de equipamento Ceptômetro Accu PAR PAR/LAI Ceptometer model LP-80 (Decagon Devices). As leituras foram realizadas entre $11 \mathrm{~h}$ e $13 \mathrm{~h}$ sob céu claro, medindo-se a intensidade luminosa acima do dossel e ao nível do solo. As medições foram realizadas nesse horário visando à redução da interferência do ângulo zenital. $O$ aparelho foi colocado perpendicularmente à linha de semeadura formando um ângulo de $45^{\circ}$ em relação ao zênite. Os dados da radiação do Ceptometer model LP-80 obtidos em $\mu \mathrm{mol} \cdot \mathrm{m}^{-2} \mathrm{~s}^{-1}$ foram transformados para $\mathrm{mol} \cdot \mathrm{m}^{-2} \cdot \mathrm{dia}^{-1}$, onde $1 \mu \mathrm{mol} \cdot \mathrm{m}^{-2} \cdot \mathrm{s}^{-1}=0,0864 \mathrm{~mol} \cdot \mathrm{m}^{-2} \cdot \mathrm{dia}^{-1}$. Os dados de RFA foram registrados em $\mu \mathrm{mol} \mathrm{s}-1$ $\mathrm{m}-2$ e convertidos em mol m $\mathrm{m}^{-2} \mathrm{~s}^{-1}$, adotando o seguinte procedimento (1):

$\mathrm{RFA}=\sum_{\text {diário }} \frac{\left(\mathrm{RFA}\left(\mu \mathrm{mol} \cdot \mathrm{m}^{-2} \cdot \mathrm{s}^{-1}\right) \mathrm{xt}(\mathrm{s})\right.}{1000000}\left(\mathrm{~mol}\right.$ de fótons $\left.\mathrm{m}^{-2} \mathrm{dia}^{-1}\right)$,

em que RFA é a radiação fotossinteticamente ativa, t é o tempo entre as coletas.

A radiação fotossinteticamente ativa interceptada (RFAint) pela cultura foi calculada da seguinte maneira (2) (VARLET-GRANCHER et al., 1989):

$\mathrm{RFA}_{\text {int }}=\mathrm{RFA}_{\text {inc }}-\mathrm{RFA}_{\mathrm{ts}}$,

em que $\mathrm{RFA}_{\text {inc }}$ é a radiação incidente e $\mathrm{RFA}_{\mathrm{ts}}$ é a radiação transmitida ao solo. A eficiência de intercepção $\left(\varepsilon_{\text {int }}\right)$ da RFA pela cultura foi estimada considerando-se a RFA $A_{\text {int }}$ e a RFA inc pela expressão (3):

$\varepsilon_{\text {int }}=\frac{\mathrm{RFA}_{\text {int }}}{\mathrm{RFA}_{\text {inc }}}$.

Por ocasião da colheita foram obtidos os seguintes caracteres: ramificações - presentes utilizando-se 3 plantas por cada unidade experimental; número de legumes - foram separadas as mesmas plantas avaliadas para a contagem do número de ramos, contando o número de legumes; massa de mil grãos - de acordo com a metodologia descrita em Brasil (2009); produtividade de grãos - padronizada para umidade dos grãos de $13 \%$ em kg ha ${ }^{-1}$.

\section{Análise estatística}

As análises de variâncias individual e conjunta foram realizadas adotando o modelo estatístico e o procedimento de análise semelhante ao apresentado por Ramalho et al. (2012). As médias foram comparadas pelo teste de Tukey a 5\% de probabilidade. A análise estatística foi realizada com o auxílio do pacote estatístico SISVAR ${ }^{\circledR}$ (FERREIRA, 2011).

\section{RESULTADOS E DISCUSSÃO}

Para as variáveis engalhamento, teor relativo de clorofila, fitomassa seca, radiação fotossintética ativa, eficiência da radiação fotossintética ativa, número de vagens, peso de mil grãos e produtividade de grãos de soja constatou-se efeito significativo da interação fontes de fósforo (A) x Safras (B). Para o estande de plantas e o índice de área foliar observou diferença estatística para a fonte de fósforo. Já para o índice de área foliar e o engalhamento a safra influenciou significativamente. A influência das fontes de fósforo nos caracteres ligados à fotossíntese das plantas pode ser explicado devido o conteúdo de fósforo nas folhas estarem 
diretamente relacionado com a quantidade de enzimas, NADPH e ATP disponíveis para o metabolismo do processo fotossintético das plantas (HENRY et al., 2012; VIEIRA et al., 2015). Diante disso, a deficiência de P pode reduzir a taxa fotossintética das plantas por afetar negativamente o número e tamanho das folhas, reduzindo, dessa forma, a área foliar necessária a uma maior captação da radiação fotossinteticamente ativa (RIPLEY et al., 2004). Nesse sentido, a adubação fosfatada é uma etapa importante no processo de produção, uma vez que, a disponibilidade desse elemento, em condições naturais, é muito baixa.

Tabela 1. Análise de variância (valores de F) para as variáveis estande de plantas (EP), índice de área foliar (IAF), engalhamento (EG), teor relativo de clorofila (TRC), fitomassa seca (FS), radiação fotossintética ativa (RFA), eficiência da radiação fotossintética ativa (ERFA), número de vagens (NV), peso de mil grãos (PMG) produtividade de grãos (PD) de soja. Analysis of variance ( $F$ values) for the plant stand $(E P)$, leaf area index (IAF), branches $(E G)$, relative chlorophyll content (TRC), dry phytomass $(F S)$, active photosynthetic radiation (RFA), the efficiency of active photosynthetic radiation (ERFA), number of pods (NV), weight of a thousand grains (PMG) soybean grain productivity (PD).

\begin{tabular}{|c|c|c|c|c|c|c|c|c|c|c|}
\hline $\begin{array}{l}\text { Fonte de } \\
\text { variação }\end{array}$ & EP & IAF & EG & $\mathrm{TRC}$ & FS & RFA & ERFA & NV & PMG & PD \\
\hline $\begin{array}{l}\text { Fósforo } \\
\text { (A) }\end{array}$ & $\begin{array}{c}177,94 \\
* *\end{array}$ & $* *$ & $\begin{array}{c}3,24 \\
\mathrm{~ns}\end{array}$ & $\begin{array}{c}2,+1 \\
\text { ns }\end{array}$ & $\begin{array}{c}24,52 \\
\text { ns }\end{array}$ & $\begin{array}{c}1063,63 \\
*\end{array}$ & $\begin{array}{l}0,029 \\
* *\end{array}$ & $\begin{array}{c}383,15 \\
\text { ns }\end{array}$ & $\begin{array}{c}0,00081 \\
*\end{array}$ & $\begin{array}{c}120338,12 \\
* *\end{array}$ \\
\hline Safras (B) & $\begin{array}{c}0,97 \\
\text { ns }\end{array}$ & $\begin{array}{c}2896293439,52 \\
* *\end{array}$ & $\begin{array}{c}115,59 \\
* *\end{array}$ & $\begin{array}{c}190,71 \\
* *\end{array}$ & $\begin{array}{c}2221,59 \\
* *\end{array}$ & $\begin{array}{c}14207,24 \\
* *\end{array}$ & $\begin{array}{c}1,278 \\
* *\end{array}$ & $\begin{array}{c}6133,87 \\
* *\end{array}$ & $\begin{array}{c}0,07174 \\
* *\end{array}$ & $\begin{array}{c}455822,5 \\
* *\end{array}$ \\
\hline$A \times B$ & $\begin{array}{c}2,76 \\
\mathrm{~ns}\end{array}$ & $\begin{array}{c}49254073,46 \\
n s\end{array}$ & $\begin{array}{c}12,88 \\
\mathrm{~ns}\end{array}$ & $\begin{array}{c}10,31 \\
*\end{array}$ & $\begin{array}{c}289,49 \\
* *\end{array}$ & $\begin{array}{c}1327,29 \\
*\end{array}$ & $\begin{array}{c}0,022 \\
* *\end{array}$ & $\begin{array}{c}1051,15 \\
* *\end{array}$ & $\begin{array}{c}0,00265 \\
* *\end{array}$ & $\begin{array}{c}296925,62 \\
* *\end{array}$ \\
\hline $\mathrm{CV}(\%)$ & 7,49 & 28 & 28,39 & 3,23 & 13,41 & 28,17 & 9,16 & 29,35 & 13,86 & 18,57 \\
\hline
\end{tabular}

**Significativo a $1 \%$ de probabilidade; *Significativo a $5 \%$ de probabilidade; ns não significativo. $\mathrm{CV}$ coeficiente de variação. **Significant at the $1 \%$ probability; $* 5 \%$ of probability; ${ }^{n}$ : not significant. CV coefficient of variation.

Fonte: Autoria própria. Own authorship.

\section{Características morfológicas estágio vegetativo}

Em relação ao índice de área foliar e o estande de plantas, observou-se que houve efeito individual das fontes de fósforo, independentemente da safra agrícola (Tabela 2). O fósforo participa de várias reações nas plantas, sendo essencial na sobrevivência e no metabolismo das mesmas, desempenhando papel importante na respiração e na fotossíntese (SARAIVA et al., 2011), justificando os resultados desse trabalho, uma vez que, as fontes de fósforo influenciam positivamente na área foliar e na sobrevivência das plantas de soja.

Todas as fontes de fósforo, SSP, SPT, FNR e FNR+S, foram eficientes no aumento do estande de plantas, com respectivos incrementos de 82,32 \%, 79,14\%, 85,82\% e 87,34\%, bem como também no aumento do índice de área foliar (IAF), com percentuais de 104,81\%, $98,44 \%, 123,16 \%$ e 146,59\%, respectivamente, quando comparado à testemunha (Tabela 3 ). $\mathrm{O}$ fato de as plantas apresentarem resposta positiva para o estande de plantas e índice de área foliar com adubação fosfatada, reforça a essencialidade do fósforo no metabolismo das plantas, exercendo papel importante na transferência de energia da célula, na respiração e na taxa fotossintética das plantas. Nesse sentido, limitações na disponibilidade desse nutriente podem resultar em restrições no desenvolvimento da planta (BONFIM-SILVA et al., 2014) e 
consequentemente na produção final. $\mathrm{O}$ incremento dessas variáveis pode ser atribuído à interação calagem e fosfatagem, que pode ter contribuído para o aumento do $\mathrm{pH}$ do solo e, consequentemente, aumento da disponibilidade de fósforo às plantas. Essas observações podem ser reforçadas por Negreiros (2014), que ao estudar a interação calcário e fontes de fósforo em solo do cerrado piauiense, observou elevação do $\mathrm{pH}$ do solo e aumento do teor de fósforo com calcário + SPT na profundidade de 0-40 cm, e também com calcário + SSP e calcário + FNR na camada de 10-20 cm.

Tabela 2. Índice de área foliar (IAF), estande de plantas (EP) de soja em função das fontes de fósforo.

\begin{tabular}{ccc}
\hline Atuação individual das fontes de & \multicolumn{2}{c}{ Variáveis } \\
\cline { 2 - 3 } fósforo & IAF & EP \\
\hline Testemunha & $0,9780 \mathrm{~b}$ & $12,56 \mathrm{~b}$ \\
SSP & $2,0032 \mathrm{a}$ & $22,90 \mathrm{a}$ \\
SPT & $1,9409 \mathrm{a}$ & $22,50 \mathrm{a}$ \\
FNR & $2,1827 \mathrm{a}$ & $23,34 \mathrm{a}$ \\
FNR+S & $2,4118 \mathrm{a}$ & $23,53 \mathrm{a}$ \\
\hline
\end{tabular}

Médias seguidas pela mesma letra minúscula na coluna de cada fator não diferem significativamente entre si pelo teste Tukey a $5 \%$ de probabilidade. SSP - superfosfato simples; SPT - superfosfato triplo; FNR - Fosfato natural reativo; FNR + S - Fosfato natural reativo + enxofre. Means followed by the same lower case letter in the lines do not differ by the Tukey test for the 5\% of probability. SSP - simple superphosphate; SPT - triple superphosphate; FNR - Reactive natural phosphate; FNR + S-Reactive natural phosphate + sulfur.

Fonte: Autoria própria. Own authorship.

Para o teor relativo de clorofila, não houve influência significativa das fontes de fósforo em relação a testemunha na safra 2013/14 (Tabela 3), entretanto, houve diferença significativa apenas entre as fontes de FNR+S e SPT na Safra 2014/15, sendo que o SPT apresentou um maior teor de clorofila. O baixo teor de clorofila com a utilização das fontes de fósforo pode ser atribuído ao maior IAF apresentado pela cultura (Tabela 2). Assim, quando se tem uma maior área foliar, também há um maior sombreamento entre as folhas. Isso pode promover uma redução no teor de clorofila na folha comparado a cultivos com maior IAF. Os resultados deste estudo corroboram com os resultados encontrados por Martins e Pitelli (2000), que ao estudarem sobre efeito da adubação fosfatada em plantas de soja, verificaram que as doses de fósforo $0,50,100$ e 200 ppm também não proporcionaram aumento do teor de clorofila na folha.

Para a fitomassa seca (FS) da soja, não houve efeito positivo das fontes de fósforo na safra 2013/14 (Tabela 3). Contudo, na safra 2014/15, as fontes SSP e FNR+S incrementaram a FS em 55,11\% e 59,07\%, respectivamente, comparado à testemunha. Resultados positivos para a matéria seca da parte aérea de soja foi observado por Martins e Pitelli (2000), com incremento de $233,44 \%$ pelo efeito da aplicação de 200 ppm de fósforo em solo com a elevação da saturação de bases a 70\%. Sousa et al. (2004) ao testar doses de fósforo obtiveram resultados positivos, com máximo acúmulo de matéria seca na dose $120 \mathrm{~kg} \mathrm{ha}^{-1}$. Dessa forma, o fósforo quando disponível para as plantas em quantidades adequadas promove maior crescimento e maior área foliar, proporcionando, maior captação da radiação solar e incremento na produção de fotoassimilados (BONFIM-SILVA et al., 2011). 
Tabela 3. Médias de estande de plantas, engalhamento e teor relativo de clorofila no florescimento da soja em função das diferentes fontes de fósforo nas safras 2013/14 e 2014/15. Averages of the plant stand, branches, and relative chlorophyll content of soybean flowering due to the different sources of phosphorus in the 2013/14 and 2014/15 cropping seasons.

\begin{tabular}{|c|c|c|c|c|c|}
\hline \multirow{2}{*}{ Safras agrícolas } & \multicolumn{5}{|c|}{ Fontes de fósforo } \\
\hline & Testemunha & SSP & SPT & FNR & $\mathrm{FNR}+\mathrm{S}$ \\
\hline & \multicolumn{5}{|c|}{ Estande de plantas $\left(\mathrm{m}^{-2}\right)$} \\
\hline Safra 2013/14 & $12,87^{\mathrm{ns}}$ & 22,68 & 23,62 & 23,12 & 23,31 \\
\hline \multirow{2}{*}{ Safra 2014/15 } & $12,25^{\mathrm{ns}}$ & 23,12 & 21,37 & 23,56 & 23,75 \\
\hline & \multicolumn{5}{|c|}{ Índice de área foliar } \\
\hline Safra 2013/14 & $1,50^{\mathrm{ns}}$ & 2,65 & 2,88 & 3,20 & 3,51 \\
\hline \multirow[t]{2}{*}{ Safra 2014/15 } & $0,44^{\mathrm{ns}}$ & 1,35 & 0,99 & 1,16 & 1,30 \\
\hline & \multicolumn{5}{|c|}{ Engalhamento (unidade planta $^{-1}$ ) } \\
\hline Safra 2013/14 & $11,75^{\mathrm{ns}}$ & 8,58 & 11,00 & 8,75 & 7,5 \\
\hline \multirow[t]{2}{*}{ Safra 2014/15 } & $5,08^{\mathrm{ns}}$ & 7,5 & 5,66 & 5,83 & 6,5 \\
\hline & \multicolumn{5}{|c|}{ Teor relativo de clorofila } \\
\hline Safra 2013/14 & $49,88^{\mathrm{ns}}$ & 48,58 & 48,5 & 49,76 & 50,24 \\
\hline \multirow[t]{2}{*}{ Safra 2014/15 } & $54,73 \mathrm{ab}$ & $54,88 \mathrm{ab}$ & $55,08 \mathrm{a}$ & $52,50 \mathrm{ab}$ & $51,59 \mathrm{~b}$ \\
\hline & \multicolumn{5}{|c|}{ Fitomassa seca $\left(\mathrm{g} \mathrm{m}^{-2}\right)$} \\
\hline Safra 2013/14 & $64 \mathrm{a}$ & $49,5 \mathrm{~b}$ & $50 \mathrm{~b}$ & $52,5 \mathrm{ab}$ & $53 \mathrm{ab}$ \\
\hline \multirow[t]{2}{*}{ Safra 2014/15 } & $28,29 \mathrm{~b}$ & $43,88 \mathrm{a}$ & $38,38 \mathrm{ab}$ & $38,91 \mathrm{ab}$ & $45 \mathrm{a}$ \\
\hline & \multicolumn{5}{|c|}{ Radiação fotossintética ativa $\left(\mathrm{Mol} \mathrm{m} \mathrm{C}^{-2} \mathrm{di}^{-1}\right)$} \\
\hline Safra 2013/14 & $105,69 \mathrm{~b}$ & $149,76 \mathrm{a}$ & $169,71 \mathrm{a}$ & $132,68 \mathrm{ab}$ & $137,07 \mathrm{ab}$ \\
\hline \multirow[t]{2}{*}{ Safra 2014/15 } & $97,19^{\mathrm{ns}}$ & 105,5 & 92,82 & 109,82 & 101,13 \\
\hline & \multicolumn{5}{|c|}{ Eficiência da radiação fotossintética ativa } \\
\hline Safra 2013/14 & $0,69 \mathrm{~b}$ & $0,96 \mathrm{a}$ & $0,95 \mathrm{a}$ & $0,91 \mathrm{a}$ & $0,92 \mathrm{a}$ \\
\hline Safra 2014/15 & $0,51^{\mathrm{ns}}$ & 0,52 & 0,53 & 0,53 & 0,56 \\
\hline
\end{tabular}

Médias seguidas pela mesma letra minúscula na linha não diferem significativamente entre si pelo teste Tukey a $5 \%$ de probabilidade. SSP - superfosfato simples; SPT - superfosfato triplo; FNR - Fosfato natural reativo; FNR + S - Fosfato natural reativo + enxofre. Means followed by the same lower case letter in the lines do not differ by the Tukey test for the 5\% of probability. SSP - simple superphosphate; SPT - triple superphosphate; FNR Reactive natural phosphate; $F N R+S$ - Reactive natural phosphate + sulfur.

Fonte: Autoria própria. Own authorship.

A radiação fotossintética ativa (RFA) da soja foi afetada pelas fontes de fósforo apenas na safra 2013/14, com incremento positivo com as fontes SSP e SPT em relação à testemunha (Tabela 3). Enquanto que, a eficiência da RFA apresentou ganhos consideráveis com todas as fontes testadas (Tabela 3). A absorção da radiação incidente pelas culturas depende do seu índice de área foliar, posição solar, geometria e tamanho da folha, ângulo de distribuição, idade, arranjo das plantas, época do ano e nebulosidade (VARLET-GRANCHER et al., 1989). Nesse sentido, percebe-se nesse estudo que as fontes proporcionaram maior estande de plantas e consequentemente maior IAF. Como a fração de área foliar é maior, há um aumento também na eficiência de uso da radiação da cultura. Isto decorre do incremento na 
contribuição relativa das folhas sombreadas para o acúmulo de biomassa da cultura, à medida que aumenta a fração difusa, e também da maior uniformidade da radiação no interior do dossel (ROSA e SANO, 2013).

O rendimento da soja está intimamente ligado a eficiência fotossintética na transformação da radiação solar interceptada e transformada em fitomassa seca, isso ocorre pelo fato de que as plantas não exibem reservas suficientes de fotoassimilados para manter o desenvolvimento das plantas e manter o potencial de produção (CARON et al., 2017). Nesse sentido, as plantas são condicionadas ao suprimento de fotoassimilados advindos da fotossíntese, a qual também é influenciada pelas condições de desenvolvimento das plantas, como a disponibilidade de fósforo no solo.

\section{Características morfológicas estágio reprodutivo}

Para os componentes de produção da soja, a análise de variância conjunta dos dados detectou diferenças significativas entre as fontes de fósforo para número de vagens, peso de mil grãos e produtividade (Tabela 4).

Tabela 4. Médias dos parâmetros produtivos da soja em função de diferentes fontes de fósforo nas safras 2013/14 e 2014/15. Averages of soybean production parameters as a function of different sources of phosphorus in the 2013/14 and 2014/15 cropping seasons.

\begin{tabular}{|c|c|c|c|c|c|}
\hline \multirow{2}{*}{ Safras agrícolas } & \multicolumn{5}{|c|}{ Fontes de fósforo } \\
\hline & Testemunha & SSP & SPT & FNR & $\mathrm{FNR}+\mathrm{S}$ \\
\hline & \multicolumn{5}{|c|}{ Número de vagens $\left(\mathrm{m}^{-2}\right)$} \\
\hline Safra 2013/14 & 82,16 a & $41,91 \mathrm{~b}$ & $48,08 \mathrm{~b}$ & $55,33 \mathrm{~b}$ & $37,08 \mathrm{~b}$ \\
\hline \multirow[t]{2}{*}{ Safra 2014/15 } & $20,58^{\mathrm{ns}}$ & 38,91 & 26,66 & 26,58 & 28 \\
\hline & \multicolumn{5}{|c|}{ Peso de mil grãos (g) } \\
\hline Safra 2013/14 & $90^{\mathrm{ns}}$ & 70 & 70 & 70 & 80 \\
\hline \multirow[t]{2}{*}{ Safra 2014/15 } & $110 \mathrm{~b}$ & $170 \mathrm{a}$ & $170 \mathrm{a}$ & $170 \mathrm{a}$ & $180 \mathrm{a}$ \\
\hline & \multicolumn{5}{|c|}{ Produtividade dos grãos $\left(\mathrm{kg} \mathrm{ha}^{-1}\right)$} \\
\hline Safra 2013/14 & $1240^{\mathrm{ns}}$ & 1017,5 & 1047,5 & 1225 & 1202,5 \\
\hline Safra 2014/15 & $856,25 \mathrm{c}$ & $1675 \mathrm{a}$ & $1431,25 \mathrm{ab}$ & $1356,25 \mathrm{~b}$ & $1481,25 \mathrm{ab}$ \\
\hline
\end{tabular}

Médias seguidas pela mesma letra minúscula na linha não diferem significativamente entre si pelo teste Tukey a $5 \%$ de probabilidade. SSP - superfosfato simples; SPT - superfosfato triplo; FNR - Fosfato natural reativo; FNR $+\mathrm{S}$ - Fosfato natural reativo + enxofre. Means followed by the same lower case letter in the lines do not differ by the Tukey test for the 5\% of probability. SSP - simple superphosphate; SPT - triple superphosphate; FNR Reactive natural phosphate; FNR +S-Reactive natural phosphate + sulfur.

Fonte: Autoria própria. Own authorship.

Para o número de vagens da soja, as fontes de fósforo contribuíram com aumento dessa variável no ano agrícola 2013/14, quando comparado com a testemunha (Tabela 4). Esses resultados se assemelham em partes aos encontrados por Guareschi et al. (2010), os quais não verificaram a influência da adubação fosfatada na quantidade de vagens por planta em relação a testemunha. Entretanto, os resultados encontrados nesse estudo para as fontes FNR e SPT corroboram com os encontrados por Richart et al. (2006), que o uso das fontes Superfosfato triplo na dose $100 \mathrm{Kg} \mathrm{ha}^{-1}$ de $\mathrm{P}_{2} \mathrm{O}_{5}$ e fosfato natural reativo na dose $200 \mathrm{Kg} \mathrm{ha}^{-1}$ de $\mathrm{P}_{2} \mathrm{O}_{5}$, 
proporcionaram médias na ordem de 48,82 e 53,23, respectivamente. Já Santos et al. (2015) encontraram resultados mais promissores com a utilização de uma dose de $246,5 \mathrm{~kg} . \mathrm{ha}^{-1} \mathrm{de}$ fósforo, atingindo 128,79 vagens por planta, o que correspondeu a um aumento de 10,4\% em relação às plantas que não receberam adubação fosfatada.

Para o peso de mil grãos (PMG) da soja, todas as fontes de fósforo interferiram positivamente nos resultados dessa variável na safra 2014/15, com aumentos de 44,68\%, $51,06 \%, 51,06 \%$ e 59,57\%, respectivamente, para SSP, SPT, FNR e FNR + S, comparado à testemunha (Tabela 4). Esse resultado sobre a eficiência da adubação fosfatada no peso de mil grãos é reforçado no trabalho de Santos et al. (2015), uma vez que, observaram que as plantas de soja apresentaram máxima resposta na maior dose de $\mathrm{P}\left(400 \mathrm{~kg} \cdot \mathrm{ha}^{-1}\right.$ de $\left.\mathrm{P}_{2} \mathrm{O}_{5}\right)$ atingindo um PMG de $169 \mathrm{~g}$, aumentando cerca de 5,5\% em relação as testemunhas em função da adubação fosfatada. Os mesmos autores relataram que nessa variável ainda é possível obter resposta significativa a doses superiores, já que o fertilizante ainda não atingiu sua máxima eficiência agronômica.

Da mesma forma, a produtividade da soja aumentou com todas as fontes de fósforo testadas na safra 2014/15, com destaque para a fonte SSP, com incremento de 95,62\% em relação à testemunha (Tabela 4). Resultados positivos com aplicação de fósforo na soja já foram confirmados por alguns pesquisadores. Alcântara Neto et al. (2010), observaram máxima resposta das plantas na dose de 94,8 kg.ha ${ }^{-1}$ de $\mathrm{P}_{2} \mathrm{O}_{5}$, com uma produtividade de $2.614 \mathrm{~kg} \cdot \mathrm{ha}^{-1}$ de grãos, aproximadamente 43,6 sc.ha- ${ }^{-1}$. Em estudo realizado por Brevilieri (2012), verificou-se que o uso de $180 \mathrm{Kg} \mathrm{ha}^{-1}$ de $\mathrm{P}_{2} \mathrm{O}_{5}$ na fonte superfosfato triplo promoveu máxima produtividade (1860,5 $\mathrm{Kg} \mathrm{ha}^{-1}$ ). Batistella et al. (2013), observaram que a adubação com $\mathrm{P}_{2} \mathrm{O}_{5}$ proporcionou um aumento da produtividade de 17,6 e $39,7 \%$ na cultura da soja na primeira e segunda safra respectivamente, em relação ao tratamento testemunha. Já Santos et al. (2015), observaram que a produtividade da soja apresentou sua máxima resposta na dose de 389,04 kg.ha- ${ }^{-1}$ de $\mathrm{P}_{2} \mathrm{O}_{5}$ com uma produção de 61,31 sc.ha ${ }^{-1}$.

Portanto, a interação calagem + fosfatagem é uma prática viável para a maximização da produtividade da soja. Dessa forma, as fontes SSP, SPT, FNR e FNR+S proporcionaram melhor desenvolvimento e maior produtividade da soja, com destaque para SSP podendo assim ser recomendada para a região do estudo.

\section{CONCLUSÃO}

As características morfofisiológicas da cultura da soja foram influenciadas pelas fontes de fósforo, conforme constatado no estande de plantas, índice de área foliar, radiação fotossintética ativa e eficiência da radiação fotossintética ativa, fitomassa seca, produtividade e no peso de mil grãos.

$\mathrm{Na}$ safra 2014/15, a fonte de fosfato natural reativo mais enxofre $(\mathrm{FNR}+\mathrm{S})$ promoveu redução no teor relativo de clorofila.

A fonte de fósforo SSP é a mais eficiente, com aumento em todas as fases fenológicas da soja 


\section{REFERÊNCIAS BIBLIOGRÁFICAS}

ALCANTÂRA NETO, F.; GRAVINA, G. A.; SOUZA, N. O. S.; BEZERRA, A. A. C. Adubação fosfatada na cultura da soja na microrregião do Alto Médio Gurguéia. Revista Ciência Agronômica, Fortaleza, v. 41, n. 2, p.266-271, 2010. Disponível em: https://doi.org/10.1590/s1806-66902010000200014. Acesso em: 12 nov. 2018.

BATISTELlA FILHO, F.; FERREIRA, M. E; VIEIRA, R. D.; CRUZ, M. C. P.; CENTURION, M. A. P. C.; SYLVESTRE, T. B.; RUIZ, J. G. C. L. Adubação com fósforo e potássio para produção e qualidade de sementes de soja. Pesquisa Agropecuária Brasileira, Brasília, v. 48, n. 7, p.783-790, 2013. Disponível em: https://doi.org/10.1590/s0100204x2013000700011. Acesso em: 04 nov. 2018.

BRASIL. Ministério da Agricultura, Pecuária e Abastecimento. Regras para análise de sementes. Brasília, DF: MAPA/ACS, 2009. 399 p.

BONFIM-SILVA, E. M.; GUIMARÃES, S. L.; FARIAS, L. N.; OLIVEIRA, J. R.; BOSA, C. K.; FONTENELLI, J. V. Adubação fosfatada no desenvolvimento e produção de feijão guandu em latossolo vermelho do cerrado em primeiro cultivo. Bioscience Journal, Uberlândia, v. $30, \quad$ n. $\quad 5$, p.1380-1388, 2014. Disponível em: http://www.seer.ufu.br/index.php/biosciencejournal/article/viewFile/18019/14982. Acesso em: 04 nov. 2018.

BONFIM-SIlVA, E. M., SIlvA, T. J., CABRAL, C. E. A.; GONÇALVES, J. M., PEREIRA, M. T. J. Produção e morfologia da leguminosa java submetida a adubação fosfatada. Enciclopédia Biosfera, Goiânia, v. 7, n. 12, p.1-10, 2011. Disponível em: http://www.conhecer.org.br/enciclop/2011a/agrarias/producao\%20e\%20morfologia.pdf.

Acesso em: 12 nov. 2018.

BREVILIERI, R. C. Adubação fosfatada na cultura da soja em latossolo vermelho cultivado há 16 anos sob diferentes sistemas de manejo. 2012. 52 f. Dissertação (Mestrado em Agronomia) - Universidade Estadual de Mato Grosso do Sul, Aquidauana, 2012.

CARON, B. O.; OLIVEIRA, D. M.; ELLI, E. F.; ELOY, E.; SCHWERZ, F.; SOUZA, V. Q. Elementos meteorológicos sobre características morfológicas e produtivas do milho em diferentes épocas de semeadura. Revista Científica, Jaboticabal, v. 45, n. 2, p.105-114, 2017. Disponível em: http://cientifica.org.br/index.php/cientifica/article/viewFile/910/565. Acesso em: 04 nov. 2018.

FERREIRA, D. F. Sisvar: A computer statistical analysis system. Ciência e Agrotecnologia, Lavras, v. 35, n. 6, p.1039-1042, 2011. Disponível em: http://dx.doi.org/10.1590/S141370542011000600001. Acesso em: 06 nov. 2018.

FREITAS, M. C. M. A Cultura da Soja no Brasil: O Crescimento da Produção Brasileira e o Surgimento de uma Nova Fronteira Agrícola. Enciclopédia biosfera, Goiânia, v. 7, n. 12, p.1-12, 2011. Disponível em: https://www.conhecer.org.br/enciclop/2011a/agrarias/a\%20cultura\%20da\%20soja.pdf. Acesso em: 04 nov. 2018. 
GUARESCHI, R. F. Emprego de fertilizantes revestidos por polímeros nas culturas da soja e milho. 2010. 44 f. Dissertação (Mestrado em Ciências Agrárias) - Instituto Federal de Educação, Ciência e Tecnologia Goiano, Rio Verde, 2010.

HENRY, A.; CHOPRA, S.; DAVID G. C.; JONATHAN P. L. Responses to low phosphorus in high and low foliar anthocyanin coleus (Solenostemon scutellarioides) and maize (Zea mays). Functional Plant Biology, Victoria, v. 39, n. 3, p.255-265, 2012. Disponível em: https://doi.org/10.1071/fp11256. Acesso em: 10 nov. 2018.

MARTINS, D.; PITELLI, R. A. Efeito da adubação fosfatada e da calagem nas relações de Interferência entre plantas de soja e capim-marmelada. Planta Daninha, Viçosa, v. 18, n. 2, p.331-347, 2000. Disponível em: https://doi.org/10.1590/s0100-83582000000200015. Acesso em: 16 nov. 2018.

NEGREIROS, A. B. Teores de nutrientes, atributos microbianos e dinâmica do fósforo em função da calagem, fosfatagem e manejo do solo no cerrado piauiense. $64 \mathrm{f}$. Dissertação (Mestrado em Agronomia - Fitotecnia) - Universidade Federal do Piauí, Bom Jesus, 2014.

NOVAIS, R. F.; ALVAREZ, V.; BARROS, N. F.; FONTES, R. L. F.; CANTARUTTI, R. B.; NEVES, J. C. L. Fósforo. In: NOVAIS, R. F.; ALVAREZ, V. H.; BARROS, N. F.; FONTES, R. L. F.; CANTARUTTI, R. B.; NEVES, J. C. L. Fertilidade do Solo. Viçosa: Sociedade Brasileira de Ciência do Solo, 2007. cap. 8, p. 471-550.

RAMALHO, M. A. P.; FERREIRA, D. F.; OLIVEIRA, A. C. Experimentação em genética e melhoramento de plantas. 2. ed. Lavras: Universidade Federal de Lavras, 2012. 514 p.

RICHART, A.; LANA, M. C.; SCHULZ, L. R.; BERTONI, J. C.; BRACCINI, A. L. Disponibilidade de fósforo e enxofre para a cultura da soja na presença de fosfato natural reativo, superfosfato triplo e enxofre elementar. Revista Brasileira de Ciência do Solo, Florianopolis, v. 30, n. 4, p.695-705, 2006. Disponível em: https://doi.org/10.1590/s010006832006000400010. Acesso em: 04 nov. 2018.

RIPLEY, B. S.; REDFERN, S. P.; DAMES, J. Quantification of the photosynthetic performance of phosphorus-deficient Sorghum by means of chlorophyll-a fluorescence kinetics. South African Journal of Science, Pretoria, v. 100, n. 11, p.615-618, 2004. Disponível em: https://journals.co.za/content/sajsci/100/11-12/EJC96177. Acesso em: 04 nov. 2018.

ROSA, R.; SANO, E. E. Determinação da produtividade primária liquida (NPP) de pastagens na bacia do rio Paranaíba, usando imagens MODIS. GeoFocus, v. 1, n. 13-1, p.367-395, 2013. Disponível em: www.geofocus.org/index.php/geofocus/article/view/274. Acesso em: 11 nov. 2018.

SANTOS, A. C. M.; CARNEIRO, J. S. S.; LEITE, R. C.; SOUZA, M. A. S.; FREITAS, G. A.; SILVA, R. R. Adubação fosfatada com fertilizante Basiduo ${ }^{\circledR}$ na cultura da soja no oeste da Bahia. Journal of Bioenergy and Food Science, Macapá, v. 2, n. 3, p.82-90, 2015. Disponível em: https://doi.org/10.18067/jbfs.v2i3.25. Acesso em: 06 nov. 2018. 
SARAIVA, K. R.; NASCIMENTO, R. S.; SALES, F. A. L.; ARAÚJO, H. F.; FERNANDES, C. N. V.; LIMA, A. D. Produção de mudas de mamoeiro sob doses de adubação fosfatada utilizando como fonte superfosfato simples. Revista Brasileira de Agricultura Irrigada, Fortaleza, v. 5, n. 4, p.376-383, 2011. Disponível em: https://doi.org/10.7127/rbai.v5n400065. Acesso em: 04 nov. 2018.

SILVA, T. O.; NETO, A. E. F.; CARNEIRO, L. F.; PALUDO, V. Plantas de cobertura submetidas a diferentes fontes de fósforo em solos distintos. Ciências Agrárias, Londrina, v. 32, n. 4, p.1315-1326, 2011. Disponível em: https://doi.org/10.5433/16790359.2011v32n4p1315. Acesso em: 04 nov. 2018.

SOUSA, D. M. G.; LOBATO, E.; REIN, T. A. Adubação com fósforo. In: SOUSA, D. M. G.; LOBATO, E. Cerrado: correção do solo e adubação. Planaltina: Embrapa Cerrados, 2004. cap. 6, p. 416.

VARLET-GRANCHER, C.; GOSSE, G.; CHARTIER, M.; SINOQUET, H.; BONHOMME, R.; ALLIRAND, J. M. Mise au point: rayonnement solaire absorbé ou intercepté par un couvert végétal. Agronomie, Paris, v. 9, n. 5, p.419-439, 1989. Disponível em: https://doi.org/10.1051/agro:19890501. Acesso em: 04 nov. 2018.

UNITED STATES DEPARTMENT OF AGRICULTURE - USDA. World Agricultural Supply and Demand Estimates (WASDE 577). 2018. Disponível em: http://usda. mannlib.cornell.edu/usda/current/ wasde/wasde-05-11-2018.pdf. Acesso em: 06 nov. 2018.

VIEIRA, C. R.; WEBER, O. L. S; SCARAMUZZA, J. F. Saturação por bases e doses de P no crescimento e nutrição de mudas de cerejeira (Amburana Acreana Ducke). Nativa, Sinop, v. 3, n. 1, p.1-9, 2015. Disponível em: https://doi.org/10.14583/2318-7670.v03n01a01. Acesso em: 02 nov. 2018. 